\title{
In vivo imaging of Lactococcus lactis, Lactobacillus plantarum and Escherichia coli expressing infrared fluorescent protein in mice
}

\author{
Aleš Berlec ${ }^{{ }^{* \dagger}}$, Janja Završnik ${ }^{2 \dagger}$, Miha Butinar ${ }^{2}$, Boris Turk ${ }^{2,3,4}$ and Borut Štrukelj ${ }^{1,5}$
}

\begin{abstract}
Background: In vivo imaging of orally administered lactic acid bacteria (LAB) and commensal bacteria in mice is shown to provide information on the spatial and temporal distribution of bacteria in the gastrointestinal tract. The bacteria can be detected and monitored using bioluminescence or near-infrared fluorescence.

Results: Fluorescence imaging of bacteria was established by expressing the infrared fluorescent protein IRFP713 in Lactococcus lactis, Lactobacillus plantarum and Escherichia coli. All three bacterial species were monitored in live mice and no major differences in transit time were observed. Bacteria passed through the stomach and small intestine in $1 \mathrm{~h}$ and the majority were secreted from the large intestine after $6-8 \mathrm{~h}$. Intestinal localization of bacteria was confirmed by imaging the isolated intestines and culturing the intestinal content. The use of fluorescence tomography for spatial localization of fluorescent bacteria has been established. The expression of an additional infrared fluorescent protein IRFP682 enabled concomitant detection of two bacterial populations in live mice.

Conclusions: The present work provides a methodological basis for future studies of probiotic and theranostic actions of $L A B$ in mouse disease models.
\end{abstract}

Keywords: In vivo imaging, Lactic acid bacteria, Lactococcus lactis, Lactobacillus plantarum, Escherichia coli, Infrared fluorescent protein, Mice

\section{Background}

In vivo optical imaging is a non-invasive method for spatial and temporal monitoring of bacteria in live animals. It can provide data on bacterial dissemination in real time and enables better use of lower numbers of experimental animals. In vivo imaging is of particular importance in the study of infectious diseases [1] and has been used to monitor the progression of infection with Salmonella typhimurium, Pseudomonas aeruginosa, Streptococcus pneumoniae and Listeria monocytogenes, etc. [1]. The majority of bacterial infection studies have been performed using bioluminescence, requiring the expression of luciferase, an enzyme that is often of bacterial origin

\footnotetext{
*Correspondence: ales.berlec@ijs.si

${ }^{\dagger}$ Aleš Berlec and Janja Završnik contributed equally to this work

${ }^{1}$ Department of Biotechnology, Jožef Stefan Institute, Jamova 39,

1000 Ljubljana, Slovenia

Full list of author information is available at the end of the article
}

(e.g. from Vibrio spp.) [1]. An alternative to bioluminescence is fluorescence. The latter requires an external light source, involves lower sensitivity and lower signal-tonoise ratio due to tissue autofluorescence. On the other hand, the fluorescence also has several advantages in comparison to bioluminescence: it does not require the administration of luciferin (which is time consuming and expensive), yields brighter signal and therefore requires shorter exposure times, and is more appropriate for combining with single-cell in vitro assays such as microscopy or flow cytometry [2-4]. Tissue autofluorescence is mini$\mathrm{mal}$ in the near infrared region between 700 and $1000 \mathrm{~nm}$ [5]. Although this spectral range is covered by organic fluorescent probes [6], they require an appropriate labelling technique and are less suitable for bacteria since they are diluted with cell division. Infrared fluorescent proteins (IFP1.4 [7] and IRFP [8]) with absorption and emission maxima in the near infrared region have recently 
been developed and expressed constitutively in bacteria. IFP1.4 has been obtained by mutagenesis of bacteriophytochrome DrBphD from Deinococcus radiodurans [7], and IRFP by mutagenesis of RpBphP2 from Rhodopseudomonas palustris [8]. Both fluorescent proteins require heme catabolic product biliverdin as a covalently-bound exogenous chromophore [8]. IRFP (aka IRFP713; GenBank accession number AEL88490) has excitation/emission maxima at 690/713 nm. Additional mutagenesis of IRFP yielded new variants with slightly different spectral properties, including IRFP682 (GenBank accession number AGN32864) with excitation/emission maxima at $663 / 682 \mathrm{~nm}$ [9]. Spectra of two proteins overlap; however they can be distinguished in vivo by spectral unmixing [9].

Lactic acid bacteria (LAB) are used routinely in the food industry and have an excellent safety record. LAB, particularly Lactobacillus spp. and Bifidobacterium spp., are also gaining importance in therapy as probiotics, due to their beneficial health effects [10-12]. Their intrinsic probiotic activity can be improved by the use of genetic engineering [13]. Genetically modified probiotic LAB can serve as vectors for local delivery of biologically active molecules to the gastrointestinal tract or other mucosal surfaces, facilitating rational targeting of pathology-related molecules [14-17]. The ability to track probiotic, as well as commensal bacteria such as E. coli, in the digestive tract of live animals would provide valuable insights of probiotic action and their interaction with commensal bacteria. Daniel et al. [18] have expressed luciferases of different origins in Lactobacillus plantarum and Lactococcus lactis in order to study bacterial persistence and precise localization in the intestine. They have shown luciferase from beetle Pyrophorus plagiophthalamus to be the most appropriate for in vivo imaging.

Several fluorescent proteins, including GFP and mCherry, have been expressed in $\mathrm{LAB}$ and used for the study of intestinal tract colonization in mouse, chicken and zebrafish [19-23]. However, due to shorter excitation and emission wavelengths of the fluorophores that overlap with high haemoglobin absorption and strong tissue autofluorescence, the animals had to be euthanized and their organs examined ex vivo.

We report the expression of IRFP in prototype LAB $L$. lactis and Lb. plantarum, and in prototype commensal/ pathogen bacterium $E$. coli to monitor and compare the bacteria in vivo in mice by the use of fluorescence. Different imaging modalities that are supported by IVIS Spectrum in vivo imager were tested. Expression of IRFP713 and IRFP682 allowed simultaneous detection of two different bacteria in a single animal by using the spectral unmixing algorithm.
The current work aims at establishing an effective in vivo fluorescence imaging platform for beneficial bacteria. In vivo imaging is expected to be one of the crucial research tools in future probiotic studies, by enabling spatiotemporal monitoring of probiotic bacteria, their interaction with the immune system and with both commensal and pathogenic bacteria. The ability to concurrently track different bacterial species will be of the greatest importance for the latter.

\section{Results}

Construction of infrared fluorescent $L$. lactis, Lb. plantarum and E. coli

Irfp 713 open reading frame was cloned into different expression vectors for the expression of IRFP713 in different hosts. Irfp 713 was expressed under the control of PnisA promoter from pNZ-IRFP713 plasmid in L. lactis NZ9000 that contains genomic copies of nisRK genes and enables induction with nisin [24]. The fluorescence intensity of IRFP713-expressing L. lactis was much higher than that of the background fluorescence of uninduced culture, vehicle control culture (containing plasmid without irfp713), or growth medium; the fluorescence intensities of the latter three were almost the same (Fig. 1a). Initial drop in fluorescence intensity from 43,000 to 25,000 FU was noted during 2 days of storage. However, after the initial drop of the fluorescence of the L. lactis culture, the latter remained relatively stable over the course of 42 days at $4{ }^{\circ} \mathrm{C}$. High bacterial viability was enumerated during the first 14 days of storage (Additional file 1: Figure S1). In comparison to L. lactis, constitutive expression of $\operatorname{irfp} 713$ (loss of responsiveness to nisin induction; Fig. 1b) was noted in Lb. plantarum, which was attributed to the introduction of nisRK genes into the backbone of pNZ-IRFP713 [25, 26]. In E. coli, irfp713 was expressed under the control of constitutive CP25 promoter in pGEM::CP25-IRFP713 plasmid [27]. IRFP713 was successfully produced in all three expression hosts, albeit different normalized fluorescence intensities to the cell concentration were observed (Fig. 2a). The highest normalized fluorescence intensity was detected in $L$. lactis, followed by Lb. plantarum and E. coli, respectively (Fig. 2a). Fluorescence of the IRFP713-expressing L. lactis, Lb. plantarum and E. coli cultures increased linearly with increasing numbers of cells (Fig. 2b). Significant differences in fluorescence were observed over a broad bacterial concentration range $\left(\mathrm{OD}_{600}=0.075-30.0\right)$, yielding a linear line on a log-log graph (Fig. $2 b$ ) with correlation coefficients exceeding 0.95 for $L b$. plantarum and 0.99 for L. lactis and E. coli, respectively.

Irfp 682 gene was prepared by site-directed mutagenesis of the $\operatorname{irfp} 713$ gene [27] and expressed in L. lactis NZ9000, as reported for the $\operatorname{irfp} 713$ gene. Fluorescence 

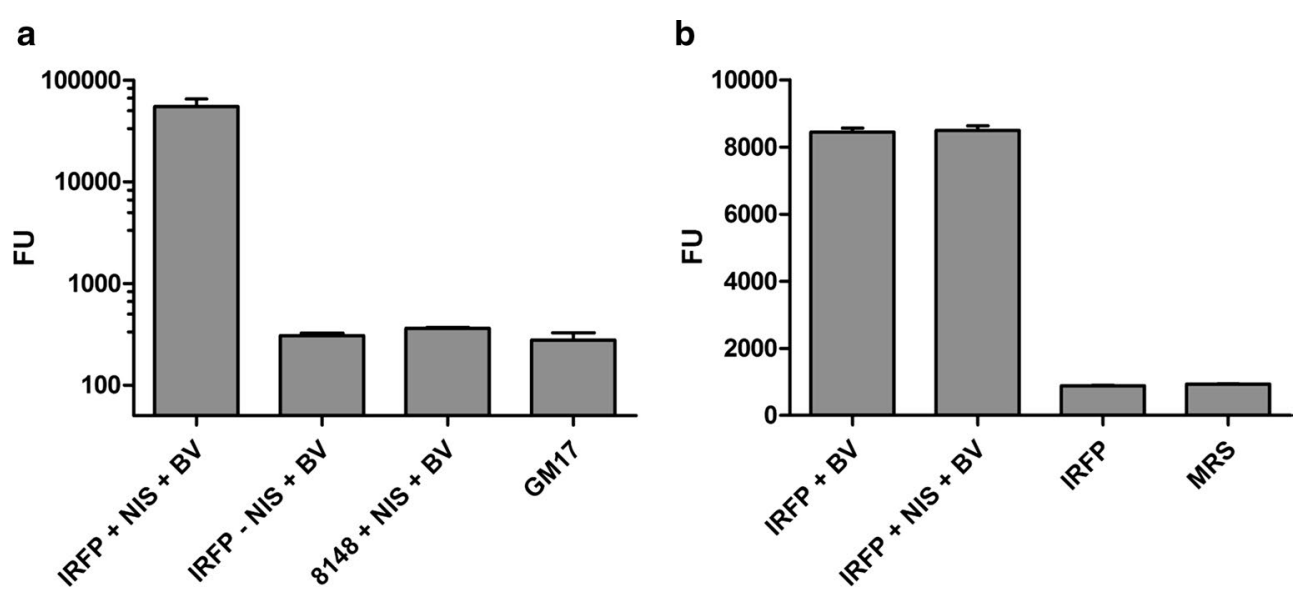

Fig. 1 Fluorescence intensity of L. lactis (a) or Lb. plantarum (b) expressing IRFP713 in comparison to various controls. IRFP denotes pNZ-IRFP713 (a) or pNZRK-IRFP713 plasmid (b). Biliverdin (BV) or nisin (NIS) were added where noted (+). 8148 pNZ8148 empty vehicle control (without irfp713 gene), GM17 M17 medium supplemented with glucose, MRS De Man, Rogosa and Sharpe medium
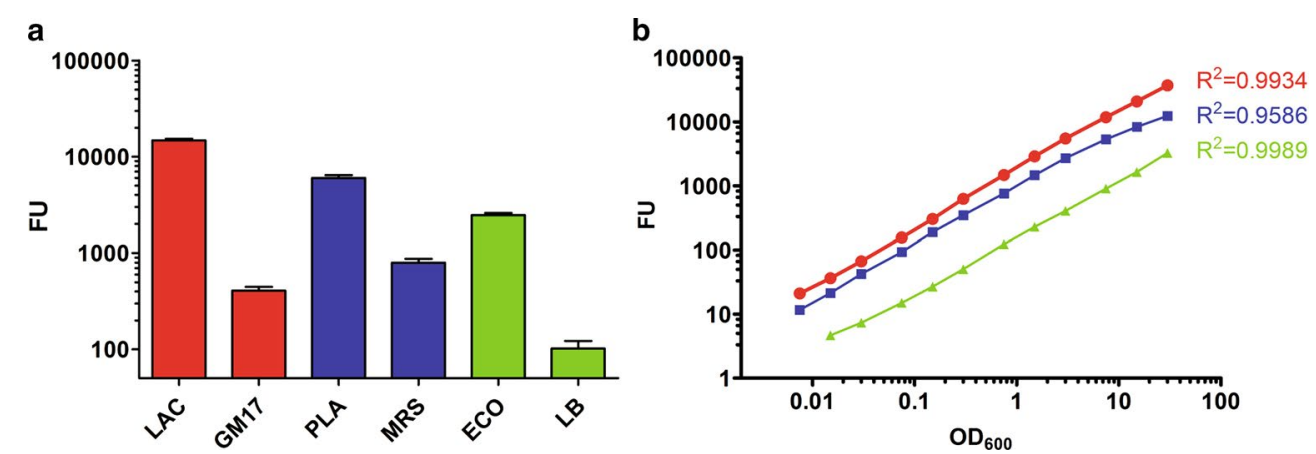

Fig. 2 Fluorescence intensity of L. lactis (LAC; red), Lb. plantarum (PLA; blue) and E. coli (ECO; green) expressing IRFP713. a Fluorescence intensity was normalized to $\mathrm{OD}_{600}=1.0$. Growth media of corresponding bacteria (GM17 M17 medium with $0.5 \%$ glucose, LB lysogeny broth, MRS De Man, Rogosa and Sharpe medium) were used as negative controls. b Fluorescence intensity of bacterial cells as a function of optical density (cell concentration). Correlation coefficients $\left(R^{2}\right)$ for individual curves are depicted in corresponding colors. FU fluorescence units, $O D_{600}$ optical density

intensities of the bacterial cultures expressing IRFP682 and IRFP713 were recorded at emission/excitation wavelengths 663/682 $\mathrm{nm}$ (optimal for IRFP682) and 690/713 nm (optimal for IRFP713; Fig. 3a). As expected, IRFP682-expressing bacteria yielded stronger fluorescence intensity at $663 / 682 \mathrm{~nm}$ and IRFP713-expressing bacteria at $690 / 713 \mathrm{~nm}$. The absolute fluorescence intensities of the two IRFP-expressing bacterial populations at their respective optimal excitation and emission wavelengths were similar. Spectral overlap was observed as reported [9], fluorescence of both proteins being observed at both emission/excitation wavelengths. The fluorescence intensity of IRFP682-expressing bacteria at $690 / 713 \mathrm{~nm}$ was significantly higher than that of the control; however, it was threefold lower than that at $663 / 682 \mathrm{~nm}$. Similarly, the fluorescence intensity of IRFP713-expressing bacteria at $663 / 682 \mathrm{~nm}$ was significantly higher than that of the control but lower than that of the IRFP682-expressing bacteria at 690/713 nm (Fig. 3a). The signals of IRFP682 and IRFP713-expressing bacteria dispensed in a microtiter plate could be completely separated with the IVIS Spectrum in vivo imager by guided spectral unmixing (Fig. 3b). The spectral properties of IRFP682- and IRFP713-expressing bacteria have been determined (Fig. $3 \mathrm{c}-\mathrm{f}$ ) and had excitation and emission maxima in accordance with those reported [9], which confirms the identity of the respective proteins. The control bacteria yielded almost no fluorescence and no excitation or emission maxima were observed (Fig. 3c-f). 
a

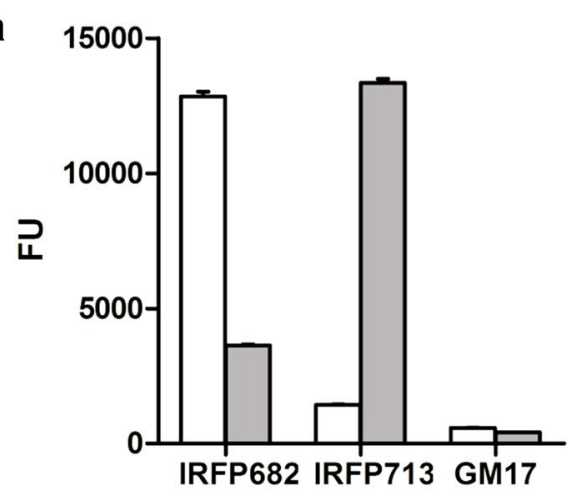

C

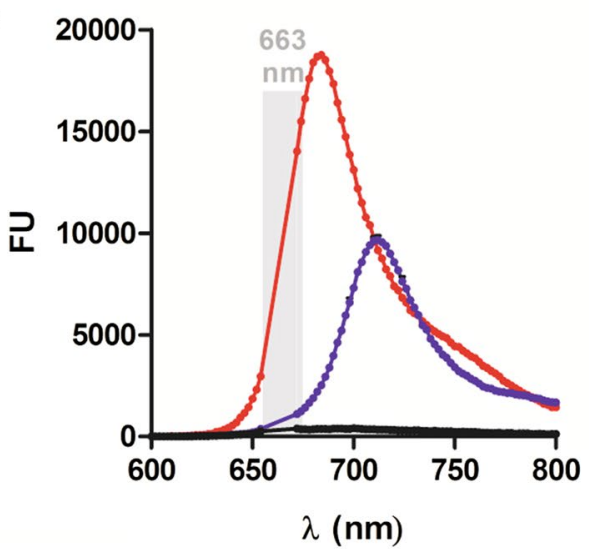

e

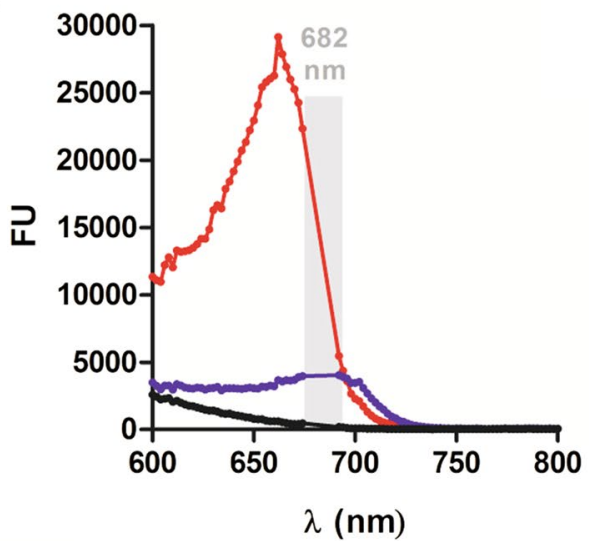

b

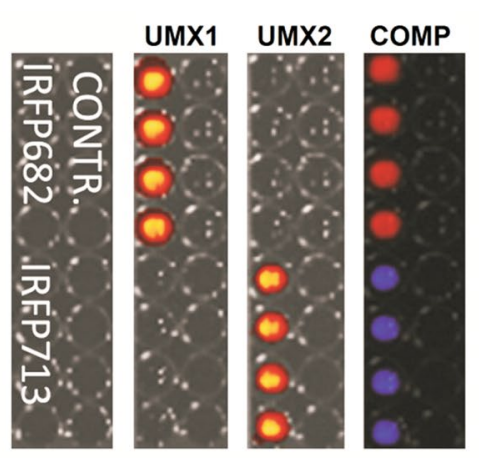

d

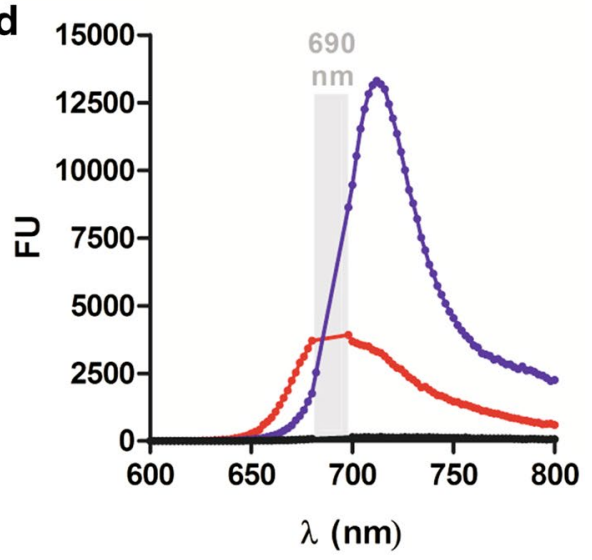

f

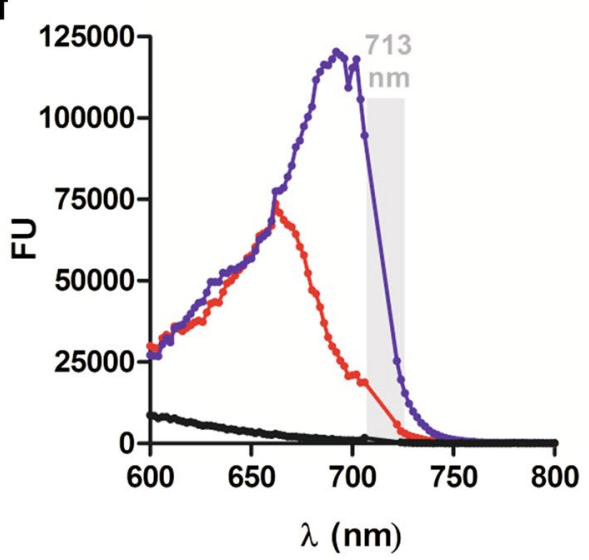

Fig. 3 Evaluation of the expression of IRFP682 and IRFP713 in L. lactis. a Fluorescence intensity of L. lactis expressing IRFP682, IRFP713 and growth medium (GM17) determined at excitation/emission wavelengths 663/682 nm (white) or 690/713 nm (gray). b Distinction of IRFP682 and IRFP713expressing lactococci, dispensed in microtiter plates, with IVIS Spectrum and spectral unmixing (Contr. empty vehicle control, UMX1 IRFP682 fluorescence, UMX2 IRF713 fluorescence, COMP. composite image). Emission (c, d) and excitation (e, f) spectra of IRFP682-expressing L. lactis (red), IRFP713-expressing L. lactis (blue) and control L. lactis (black), recorded at wavelengths specified in gray. Gray belts denote excitation and emission wavelengths at which reliable read-outs could not be obtained due to the vicinity of the wavelength used to record the spectrum

In vivo reflectance (epifluorescence) time-course imaging of mice following oral administration of IRFP713-expressing bacteria

Three mice were administered $5.0 \times 10^{10}$ IRFP713expressing $L$. lactis cells to determine the time profile of the IRFP713 signal following oral administration of bacteria (Fig. 4). The IRFP713 signal at a given time point was reconstituted from a sequence of nine images recorded with different filter pair combinations using spectral unmixing (Additional file 2: Figure S2). Localization of 


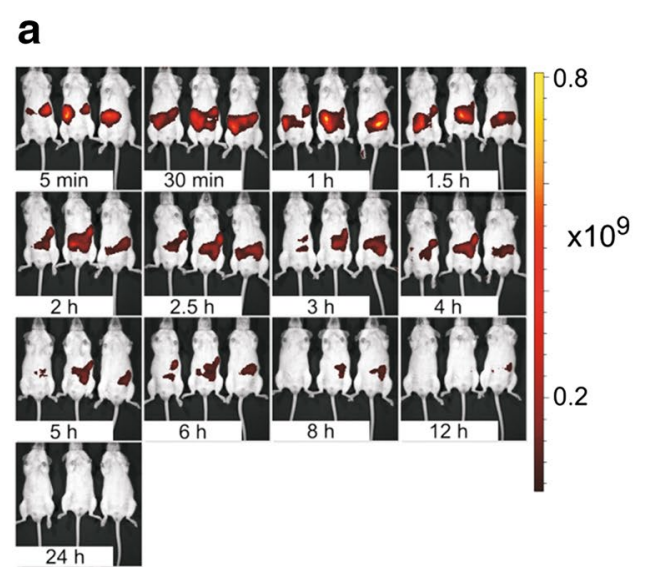

b

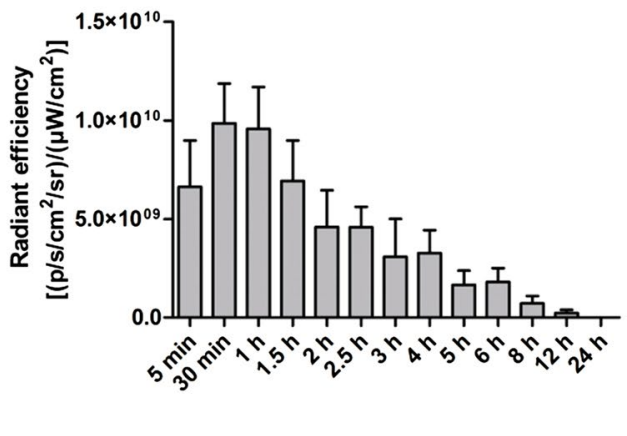

Fig. 4 Time-course (24 h) imaging of mice administered with $5.0 \times 10^{10}$ cells of IRFP713-expressing L. lactis. a Reflectance (epifluorescence) image with a color bar indicating radiant efficiency $\left[\left(\mathrm{p} / \mathrm{s} / \mathrm{cm}^{2} / \mathrm{sr}\right) /\left(\mu \mathrm{W} / \mathrm{cm}^{2}\right)\right]$. b Radiant efficiency of IRFP713-expressing L. lactis in mice as a function of time. Vertical bars indicate standard error

the bacterial mass changed over time and was similar in all three mice (Fig. 4a). Radiant efficiency achieved maximum level $\left(9.86 \times 10^{9}-9.56 \times 10^{9}\right)$ between $30 \mathrm{~min}$ and $1 \mathrm{~h}$ after the administration. It then decreased gradually over the course of $24 \mathrm{~h}$, indicating secretion and bacterial dilution along the entire volume of the intestinal tract. After $8 \mathrm{~h}$, only weak radiant efficiency was observed in two mice $\left(2.27 \times 10^{8}\right)$, and after $12 \mathrm{~h}$ in only one mouse. After $24 \mathrm{~h}$ no fluorescence was observed, indicating elimination of the L. lactis bacteria from the intestine (Fig. 4).

To visualize the dynamics of the bacterial mass during the first hour after administration, a time course was recorded at 5-10 min intervals following administration of $5.0 \times 10^{10}$ cells of IRFP713-expressing L. lactis, E. coli and Lb. plantarum (Fig. 5). All three bacterial species were readily detected in mice although the average radiant efficiency was different between the species $\left(1.3 \times 10^{8}\right.$ E. coli, $1.9 \times 10^{9} \mathrm{Lb}$. plantarum, $4.6 \times 10^{9} \mathrm{~L}$. lactis), due to the differences in normalized fluorescence observed between the different bacterial cells (Fig. 1). The exception was $E$. coli that yielded a fivefold lower signal than expected. The fluorescence intensity for a particular species remained relatively constant during the $1 \mathrm{~h}$ time course; although differences in localization of bacterial mass were readily observed.

\section{Ex vivo epifluorescence time-course imaging of mouse intestine following oral administration of IRFP713-expressing bacteria}

The passage of $5.0 \times 10^{10}$ cells of IRFP713-expressing L. lactis through individual parts of the intestine (stomach, small intestine, caecum, large intestine) as a function of time was determined by removing their intestines at specified time points and epifluorescence imaging
(Fig. 6a). Bacteria were quantified by determining radiant efficiencies in individual parts of the intestine (Fig. 6b). Radiant efficiencies correlated with the number of viable bacteria $\left(\mathrm{CFU} / \mathrm{cm}^{2}\right)$ isolated from different parts of the intestine (Fig. 6c) at corresponding time points. The strongest correlation was calculated for caecum $\left(R^{2}=0.970\right)$ and large intestine $\left(R^{2}=0.951\right)$, but lower for stomach $\left(R^{2}=0.622\right)$ and small intestine $\left(R^{2}=0.819\right)$. Bacterial boluses were detected in the stomach and in the small intestine $5 \mathrm{~min}$ after administration. In the first $60 \mathrm{~min}$ bacteria passed through the small intestine and reached the caecum. They were retained in the caecum for several hours; from there they gradually cleared to the large intestine from which more than $90 \%$ were secreted in $10 \mathrm{~h}$, as observed by the decrease in both, CFU number and radiant efficiency (Fig. 6b, c).

Mice were also administered with $5.0 \times 10^{10}$ cells of IRFP713-expressing $E$. coli and $L b$. plantarum. Similar profiles of intestinal transit as with $L$. lactis were observed in isolated intestine for both $L b$. plantarum (Fig. 7a) and E. coli (Fig. 7b). However, the E. coli signal diminished $4 \mathrm{~h}$ after administration, indicating faster secretion or lower intensity of the E. coli signal, which was further weakened by bacterial dilution.

\section{Time-course fluorescence tomography imaging of IRFP713-expressing bacteria}

Eleven mice were administered with $5.0 \times 10^{10}$ cells of IRFP713-expressing L. lactis and euthanized at defined time points over the course of $24 \mathrm{~h}$. Fluorescence imaging tomography (FLIT) images of intact mice were recorded at each time point, using trans-illumination, and compared with the epifluorescence images of intact mice, images of mice with open abdominal cavity, and with the 


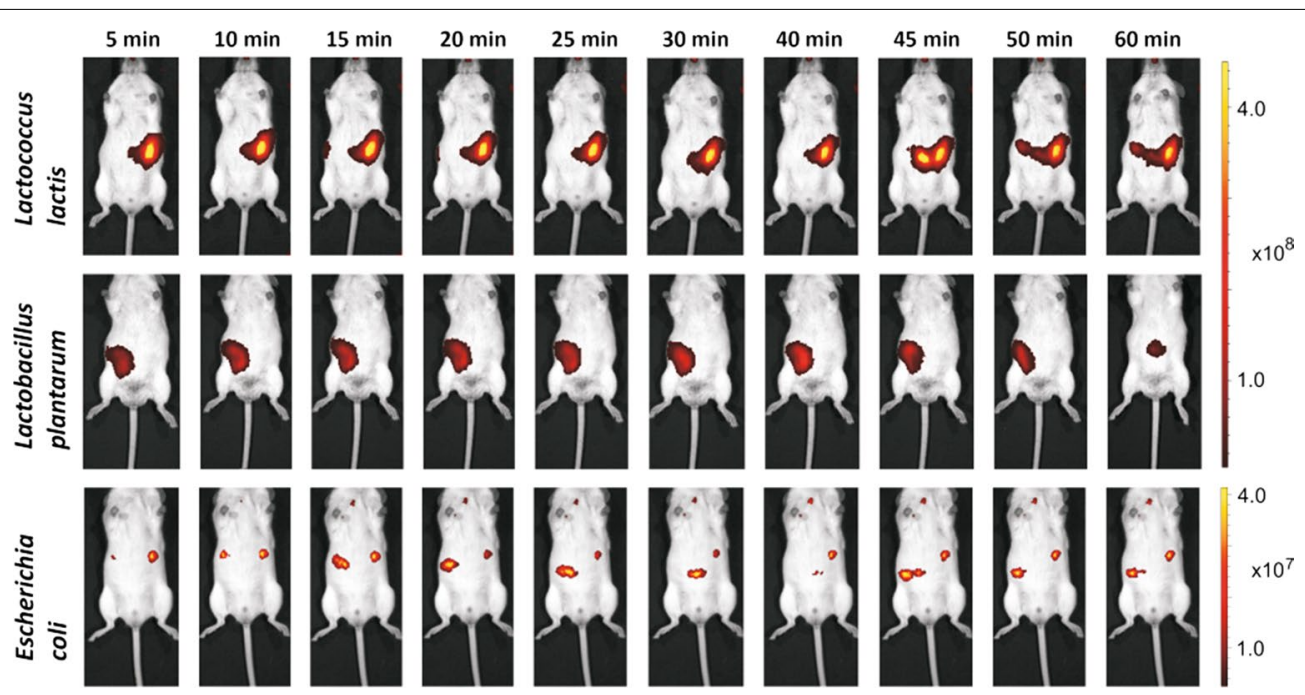

Fig. 5 Representative time-course (1 h) imaging of mice receiving $5.0 \times 10^{10}$ cells of IRFP713-expressing L. lactis (upper row), Lb. plantarum (middle row) and E. coli (bottom row). Color bars indicate radiant efficiency $\left[\left(\mathrm{p} / \mathrm{s} / \mathrm{cm}^{2} / \mathrm{sr}\right) /\left(\mu \mathrm{W} / \mathrm{cm}^{2}\right)\right]$

epifluorescence images of isolated intestines. Very good correlation of spatial distribution of bacterial mass was observed in the first $3 \mathrm{~h}$ after administration between FLIT images, epifluorescence images and epifluorescence images of mice with open abdominal cavity (Fig. 8). Precise localization of bacterial mass could be determined using isolated intestine. Clear spatial separation between stomach (5 $\mathrm{min})$, small intestine $(20,40 \mathrm{~min})$, caecum (60 $\mathrm{min})$ and large intestine $(1.5,2 \mathrm{~h})$ was observed. The radiant efficiencies of the intestines decreased over time due to the considerable secretion, from $4.37 \times 10^{9}$ to $5.85 \times 10^{9}$ during the first hour, to $1.13 \times 10^{8}-$ $2.84 \times 10^{8}$ in the period of 3-6 h after administration, and $5.54 \times 10^{6}-9.24 \times 10^{6}$ in the period of $8-12 \mathrm{~h}$ after administration.

\section{Differentiation between IRFP682 and IRFP713-expressing bacteria in vivo and in isolated intestine}

To verify the differentiation between IRFP682 and IRFP713-expressing bacteria in vivo, mice were administered with $5.0 \times 10^{10}$ cells of IRFP682- and IRFP713expressing L. lactis. Spectral unmixing was used to distinguish the fluorescence of IRFP682, IRFP713 and background tissue autofluorescence (Additional file 3: Figure S3). Fluorescence of both IRFP-expressing bacterial species in the separate mice was detected and differentiated by spectral unmixing $5 \mathrm{~min}$ after administration (Fig. 9a). After $2 \mathrm{~h}$, the mouse previously administered with IRFP682-expressing bacteria was further administered with $5.0 \times 10^{10}$ cells of IRFP713-expressing bacteria. Signals of both bacterial species were detected and separated in a single mouse (Fig. 9b; middle mouse). In a separate experiment, the two bacterial species could also be differentiated in the intestine of the mouse that was administered with both bacterial species. Immediately following the administration of IRFP713-expressing bacteria, they were detected only in the stomach and at the beginning of the small intestine. IRFP682-expressing bacteria that were administered $2 \mathrm{~h}$ earlier, on the other hand, had already reached the caecum and large intestine, but were also still present in the stomach (Fig. 9c).

\section{Discussion}

IRFP713 has been expressed in three bacterial hosts, two LAB (L. lactis, Lb. plantarum) and model commensal/pathogenic bacterium $E$. coli, via inducible or constitutive expression system. The identity of IRFP713 was confirmed by determining the spectral properties; these corresponded to those determined previously [8]. IRFP713 was codon-optimized for $L$. lactis and therefore optimally suited for expression in this organism, as confirmed by the highest normalized fluorescence intensity. The fluorescence intensity of the IRFP713-expressing cell culture correlated with the optical density (cell concentration), and can be used for bacterial quantification [27, 28]. A linear relationship between the fluorescence intensity and the cell concentration was observed in cultures of all three bacterial species over a broad range of bacterial concentrations, facilitating precise quantification of bacteria in the culture. The background fluorescence of control bacteria was very low and did not differ from that of the growth medium. The fluorescence intensity of the IRFP713-expressing L. lactis culture and viability of the bacteria were shown to persist for much longer (50 

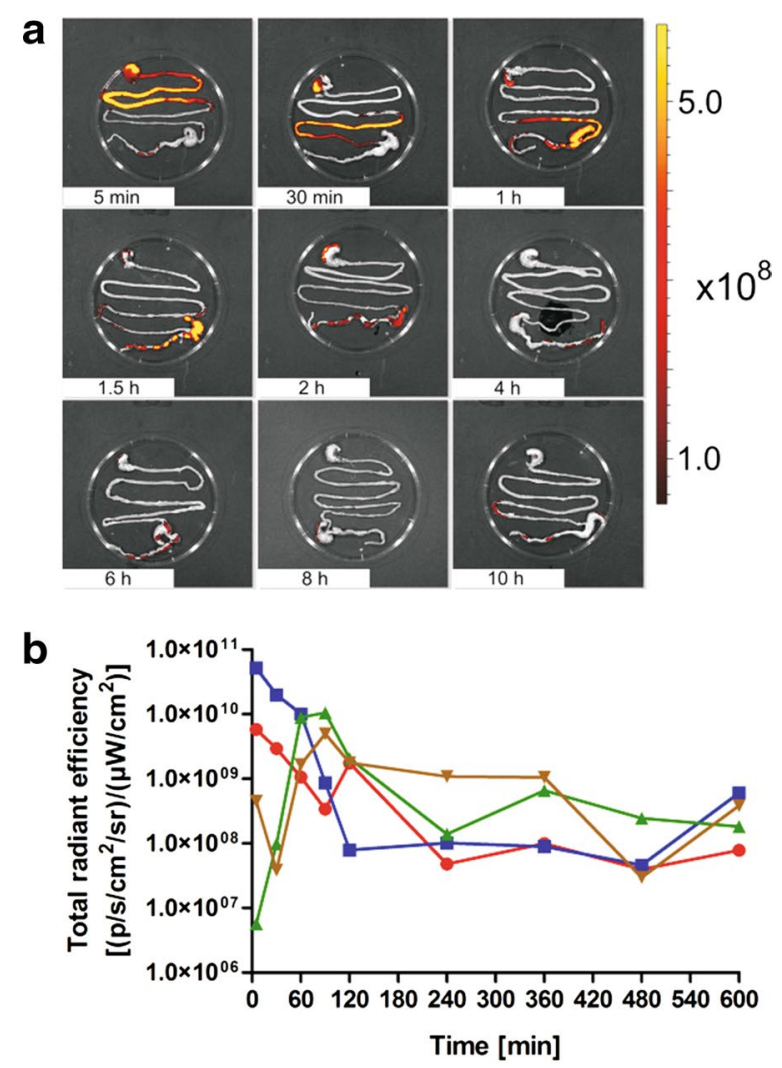

C

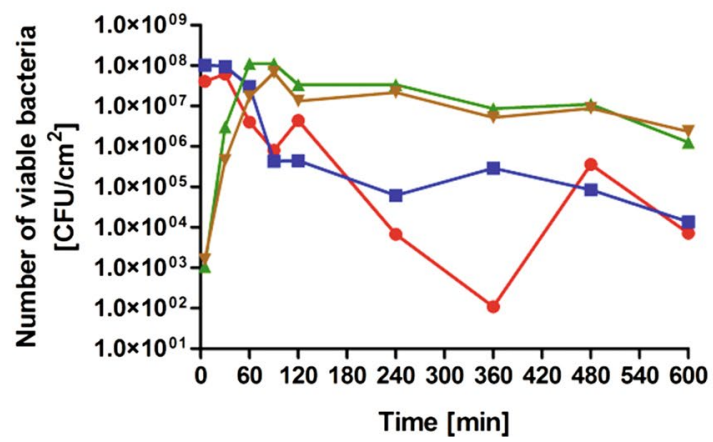

Fig. 6 Transit and survival of IRFP713-expressing L. lactis in mice. Mice were administered with $5.0 \times 10^{10}$ cells. Intestines were extracted at different time points and recorded by epifluorescence imaging (a). Radiant efficiencies $\left[\left(\mathrm{p} / \mathrm{sec} / \mathrm{cm}^{2} / \mathrm{sr}\right) /\left(\mu \mathrm{W} / \mathrm{cm}^{2}\right) ; \mathbf{b}\right]$ and numbers of viable bacteria $\left(\mathrm{CFU} / \mathrm{cm}^{2} ; \mathbf{c}\right)$ were determined in different parts of the intestine as a function of time. Stomach is shown in red, small intestine in blue, caecum in green, and large intestine in brown

and 14 days, respectively) than the period of the animal experiments (maximum $24 \mathrm{~h}$ ). This allows the assumption that the gradual decrease in fluorescence in animal experiments (described below) is due to bacterial secretion and not to IRFP713 degradation or bacterial cell lysis. The fluorescence is not necessarily related to viable bacteria [27]; however free IRFPs would probably be degraded or denatured under intestinal conditions.
Intestinal bacterial viability was confirmed by successful isolation of the bacteria from different parts of the mouse intestine.

IRFP713 enables excitation/emission in the near-infrared region $(690 / 713 \mathrm{~nm})$, which should minimize the autofluorescence of background tissue. In practice, however, the autofluorescence in this spectral range was still considerable and prevented exact localization of the signal source and estimation of its strength. This was partly circumvented by the use of a chlorophyll-minimized (alfalfa-free) diet [29]. The fluorescence intensity could be further increased by using nude or shaved mice; however, this was not considered in the present research. The IRFP713 signal was readily distinguished from the background by using spectral unmixing in reflectance (epifluorescence) imaging.

Different imaging modalities were employed to monitor the fate of the bacteria after administration to mice. Epifluorescence imaging is straightforward and fast. However, quantification of the fluorescence signal is limited, as it depends on both the fluorescence intensity of the source and its depth inside the animal body (distance from the surface) [4]. While the ratio of fluorescence of IRFP713-expressing L. lactis and Lb. plantarum measured in vivo corresponded to that determined in vitro, the fluorescence intensity of IRFP713-expressing $E$. coli was lower. Epifluorescence imaging of three mice that were administered simultaneously with IRFP713expressing L. lactis resulted in considerable standard errors. Nevertheless, the time dependent decrease in fluorescent signal caused by bacterial secretion was in agreement with other approaches that were used (ex vivo imaging of intestines, fluorescence tomography). Epifluorescence imaging was used primarily for qualitative localization of the signal source, rather than source quantification. When comparing epifluorescence images of intact animals with those of mice with open abdominal cavities, or with tomographic images, considerable agreement was observed. However, despite effective separation of IRFP713 fluorescence from the tissue autofluorescence, reconstruction of the exact position of the source of the signal and its annotation to a specific organ is difficult. During the first hour after administration of different bacterial species, when the bacteria traverse the small intestine (discussed below) the movements of the bacterial mass could be observed, but reconstitution of its positioning in the small intestine was limited. Annotation of the source of the signal to a specific organ could be improved by the use of computed tomography scan.

Exact positioning of all three species of fluorescent bacteria was achieved by epifluorescence ex vivo imaging of isolated intestines, in which the tissue thickness is minimal. The quantification achieved by measuring 

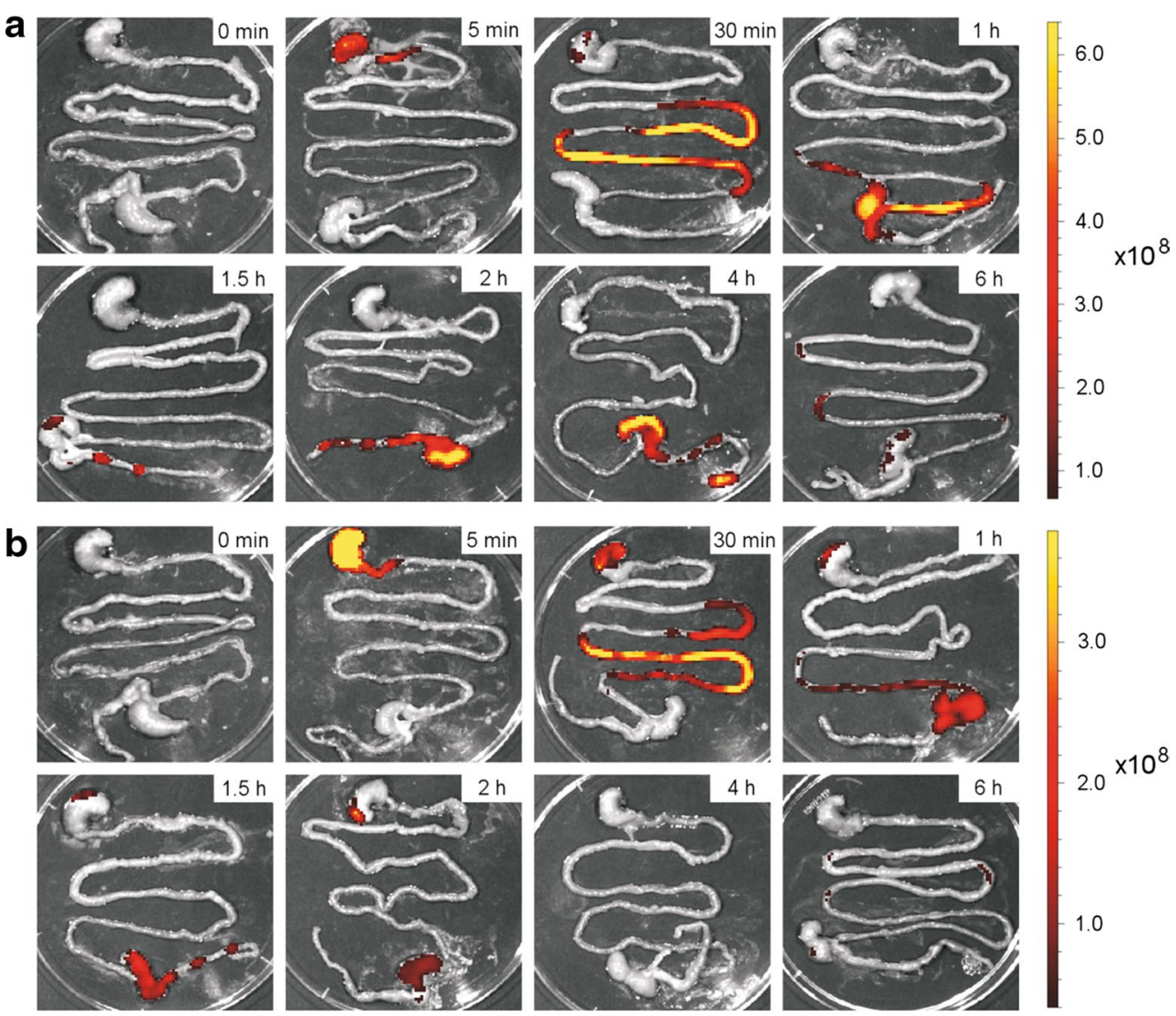

Fig. 7 Ex vivo imaging of mouse intestines extracted at different time points after administration of $5.0 \times 10^{10}$ cells of IRFP713-expressing Lb. plantarum (a) and E. coli (b). Color bars indicate radiant efficiency $\left[\left(\mathrm{p} / \mathrm{s} / \mathrm{cm}^{2} / \mathrm{sr}\right) /\left(\mu \mathrm{W} / \mathrm{cm}^{2}\right)\right]$

radiant efficiencies in different parts of the intestine was verified by isolating and determining the count of viable bacteria in the corresponding intestinal parts. Good correlations were observed for caecum and large intestine, and somewhat lower correlations for stomach and small intestine, probably due to faster transit through the latter two organs. However, ex vivo imaging is an approach that only partially fulfils the aim of the present study, namely in vivo imaging.

To resolve the exact positioning of the bacteria in the whole animal fluorescence tomography (FLIT), that requires transillumination fluorescence measurements, was applied. FLIT enabled spatial reconstruction of IRFP713-expressing bacteria at given time points. Due to the complexity, spectral unmixing combined with FLIT is not feasible in time-course experiments and was not employed. Nevertheless, comparison of FLIT with epifluorescence images of whole animals and animals with an open abdominal cavity revealed very good agreement between different imaging techniques. This suggests that the FLIT technique is suitable for in vivo monitoring of IRFP-expressing bacteria.
All imaging modalities were employed for determining the time-course of transit of three bacterial species in live mice in a $24 \mathrm{~h}$ time window. The results of epifluorescence imaging of live mice, tomographic (FLIT) imaging, ex vivo epifluorescence imaging of isolated intestines and culturing of the bacteria from different parts of the intestine were in agreement. To summarize, bacterial mass reached the stomach immediately after administration. After approximately $1 \mathrm{~h}$, bacteria passed through the small intestine and reached the caecum. In some experiments longer bacterial retention in the stomach was observed, possibly due to inter-animal differences in feeding prior to administration, or to coprophagy. From the caecum the bacteria entered the large intestine and were gradually secreted from the organism. Bacteria were barely detectable $6-8 \mathrm{~h}$ after the administration, using imaging techniques, due to considerable secretion and dilution, and were no longer detected after $24 \mathrm{~h}$. The observed intestinal transit data correspond to those reported [29]. No major differences were observed between different bacterial species, as inferred from the ex vivo epifluorescence imaging of isolated intestines. 


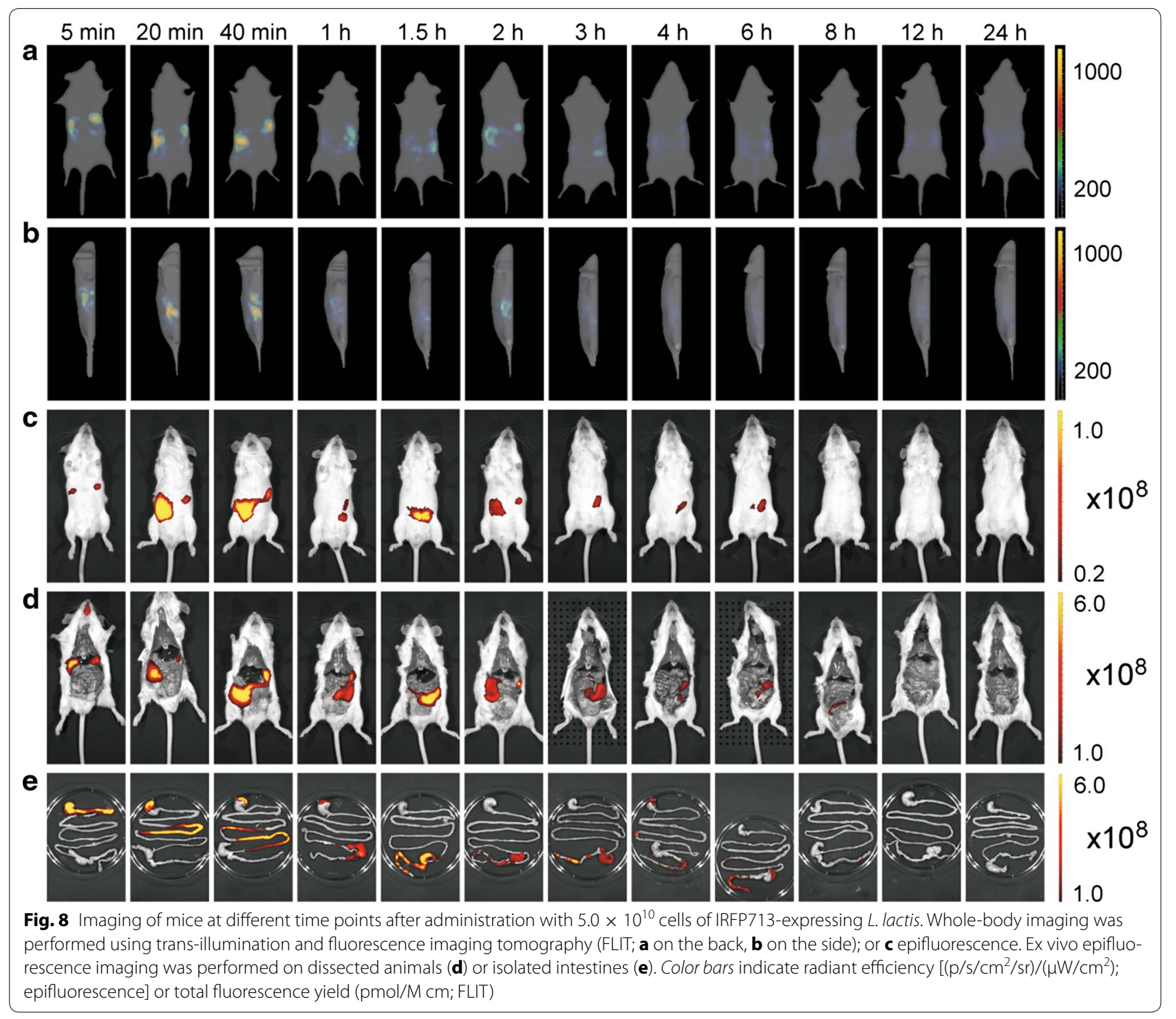

However, the differences in normalized fluorescence intensity between bacterial species somewhat hindered comparison of transit times. This was particularly evident with $E$. coli that had the lowest normalized fluorescence and therefore resulted in the apparently fastest clearance from the organism.

One of the potential advantages of in vivo fluorescence imaging is the concomitant monitoring of multiple fluorescent proteins with different spectral properties. A palette of different IRFPs has recently been introduced [9]. The gene for the IRFP variant IRFP682 was obtained by site-directed mutagenesis and expressed in L. lactis. Its identity was confirmed by spectral properties in the bacterial culture that corresponded to those reported previously
[8]. The considerable spectral overlap of IRFP682 and IRFP713 prevents distinguishing them with FLIT. On the other hand, the epifluorescence signals of IRFP682 and IRFP713 can be distinguished from each other by spectral unmixing. A population of $L$. lactis expressing IRFP713 was distinguished from one expressing IRFP682 in vivo in mice and ex vivo in isolated intestine. However, it should be noted that the two bacterial species can be more effectively resolved by spectral unmixing if they are sufficiently separated spatially. The fluorescence signal is less reliably unmixed if there is a significant bacterial overlap (e.g., bacterial mixture in a single organ). The resolution of bacterial populations could be further improved by using photoacoustic tomography [30]. 


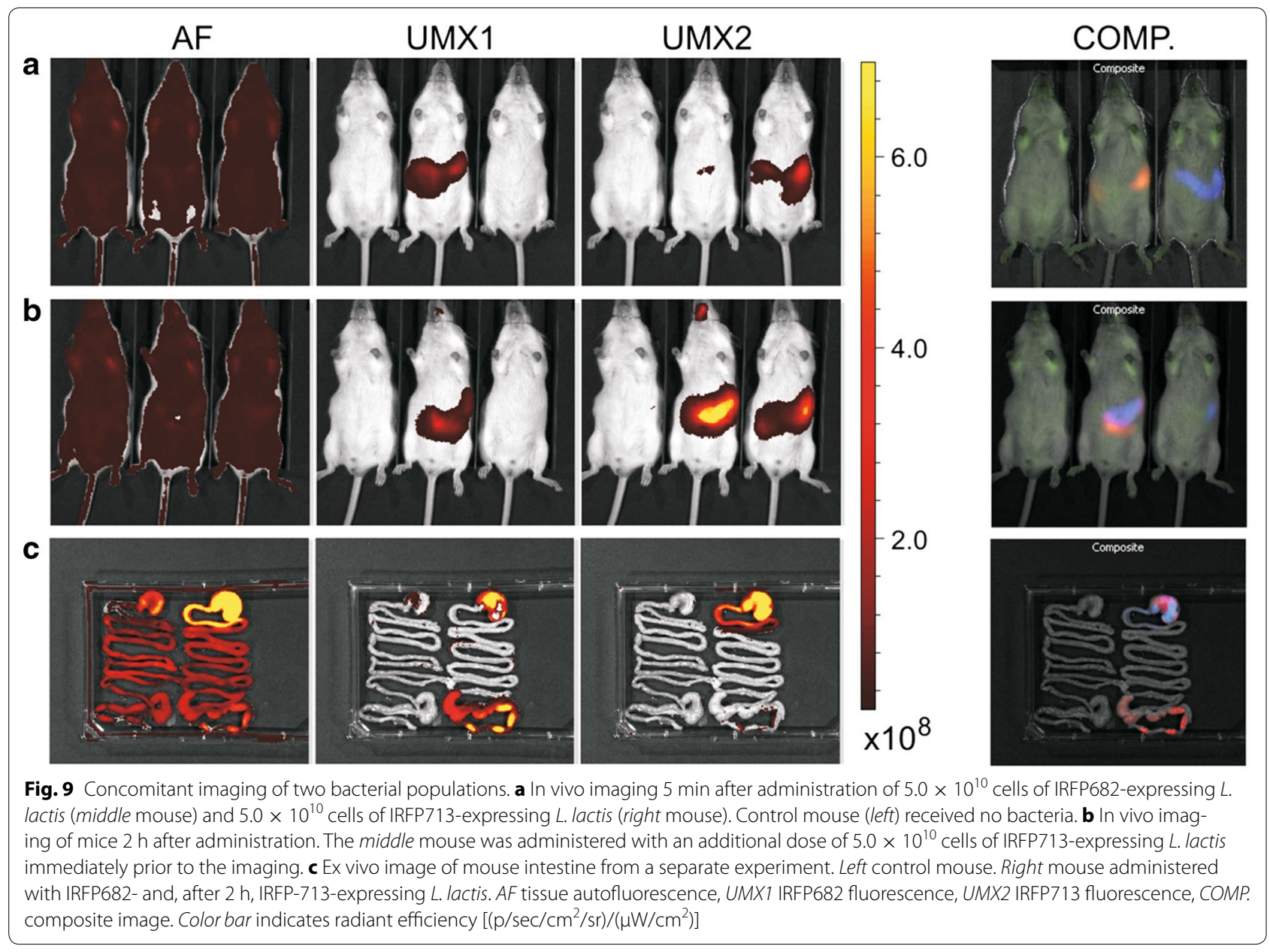

\section{Conclusions}

The feasibility of using fluorescence for in vivo monitoring of LAB in mice has been demonstrated in the present work. Near-infrared fluorescent protein IRFP713 was expressed in two LAB species (L. lactis, Lb. plantarum) and in a model commensal/pathogen bacterium, E. coli, and was detected directly in a bacterial culture without the need for removal of the growth medium, indicating its potential as a reporter protein in various bacteria. All three bacterial species were imaged in live mice with IVIS Spectrum, using fluorescence reflectance imaging (epifluorescence) or fluorescence tomography. The data were supplemented by epifluorescence imaging of isolated intestines ex vivo. The ability to monitor the gastrointestinal transit time of bacteria was demonstrated, as well as their spatial localization. Viable bacteria were isolated and cultured from different parts of the intestine and their quantity corresponded to the fluorescence signal determined by imaging. Two IRFPs, differing in their spectral properties, were expressed in L. lactis.
Populations of bacteria expressing IRFP713 and IRFP682 were distinguished in vivo, enabling their concomitant monitoring. A platform for future studies of probiotic and theranostic effects of LAB in mouse disease models, as well as their interaction with commensal or pathogenic bacteria, has thus been established.

\section{Methods}

\section{Bacterial strains, media and culture conditions}

The bacterial strains used in this study are listed in Table 1. L. lactis NZ9000 was grown at $30{ }^{\circ} \mathrm{C}$ in $\mathrm{M}-17$ medium (Merck) supplemented with $0.5 \%$ glucose (GM17) and $10 \mu \mathrm{g} / \mathrm{mL}$ chloramphenicol without aeration. Lactobacillus plantarum ATCC 8014 was grown at $37^{\circ} \mathrm{C}$ in De Man, Rogosa and Sharpe (MRS) medium (Merck) supplemented with $10 \mu \mathrm{g} / \mathrm{mL}$ chloramphenicol, without aeration. E. coli $\mathrm{DH} 5 \alpha$ was grown at $37^{\circ} \mathrm{C}$ with aeration in lysogeny broth (LB) supplemented with $100 \mu \mathrm{g} / \mathrm{mL}$ ampicillin. Media were supplemented with $15.5 \mu \mathrm{g} / \mathrm{mL}$ biliverdin $\mathrm{HCl}$ (Sigma Aldrich). 
Table 1 Strains, plasmids, gene and primers

\begin{tabular}{|c|c|c|}
\hline Bacteria, plasmid, or gene & Relevant features or sequence $\left(5^{\prime}-3^{\prime}\right)$ & $\begin{array}{l}\text { References or } \\
\text { sources }\end{array}$ \\
\hline \multicolumn{3}{|l|}{ Bacteria } \\
\hline E. coli DH5a & $\begin{array}{l}\text { endA1 glnV44 thi-1 recA1 relA1 gyrA96 deoR F- } \$ 80 d / a c Z \Delta M 15 \triangle(\text { lacZYA-argF)U169, } \\
\text { hsdR17(rK- mK +), } \lambda-\end{array}$ & Invitrogen \\
\hline L. lactis NZ9000 & MG1363 nisRK $\triangle p e p N$ & $\mathrm{NIZO}[35,36]$ \\
\hline Lb. plantarum ATCC 8014 & Wild type & ATCC \\
\hline \multicolumn{3}{|l|}{ Plasmid } \\
\hline pNZ8148 & pSH71 derivative, PnisA, CmR, nisin-controlled expression & NIZO $[35,36]$ \\
\hline pNZRK & pNZ8148 containing nisR and nisK genes & This work \\
\hline pNZ-IRFP713 & pNZ8148 containing irfp713 gene & This work \\
\hline pNZ-IRFP682 & pNZ8148 containing irfp682 gene & This work \\
\hline pNZRK-IRFP713 & pNZ8148 containing irfp 713 , nis $R$ and nisK genes & This work \\
\hline PMA-T-IRFP713 & pMA-T containing irfp 713 gene & This work \\
\hline pMSP3545 & $\mathrm{Em}^{r}, \mathrm{P}_{\text {nisA, }}$ nisRK, Ncol for translational fusion, ColE1 and pAM $\beta 1$ replicons & [37] \\
\hline pMSP3545-IRFP713 & pMSP3545 containing irfp713 gene & This work \\
\hline pGEM::CP25-IRFP & pGEM-T Easy containing irfp 713 gene under the control of CP25 promoter & [27] \\
\hline \multicolumn{3}{|l|}{ Gene } \\
\hline $\operatorname{irfp} 713$ & $\begin{array}{l}\text { CCATGGCTGAGGGATCTGTAGCTCGTCAACCTGATTTACTTACTTGTGACGATGAACCTATTCATATTCC } \\
\text { AGGTGCTATTCAACCACACGGACTTTTATTAGCTCTTGCCGCTGACATGACTATCGTCGCTGG } \\
\text { ATCAGATAATTTACCTGAATTGACTGGTTTAGCAATTGGAGCCCTTATTGGACGATCAGCAGCAG } \\
\text { ATGTTTTTGATTCAGAAACTCATAATCGTCTTACTATTGCATTGGCAGAACCTGGTGCTGCAGTAGG } \\
\text { TGCTCCTATTACAGTAGGTTTCACTATGCGTAAGGATGCTGGTTTTATTGGTTCTTGGCATCGTC } \\
\text { ATGATCAACTTATTTTTTTAGAGTTGGAACCACCACAAAGAGACGTTGCAGAGCCTCAAG } \\
\text { CTTTTTTTCGTCGTACTAATTCAGCAATTCGTAGACTTCAAGCTGCTGAAACTCTTGAATCTGCATGTG } \\
\text { CAGCAGCAGCACAAGAGGTACGAAAAATTACAGGTTTTGATAGAGTTATGATTTACAGATTTGCC } \\
\text { TCAGACTTTTCTGGTGAAGTAATCGCAGAGGATAGATGTGCCGAGGTTGAAAGTAAATTGGGATTGC } \\
\text { ATTATCCTGCCAGTACTGTTCCAGCCCAAGCACGTCGTCTTTATACTATTAATCCTGTTAGAATTATCC } \\
\text { CAGATATTAATTATCGACCAGTTCCAGTTACTCCTGACTTAAATCCTGTAACTGGTAGACCTATTG } \\
\text { ACTTGTCATTTGCCATCTTACGATCTGTTCACCTGTTCATTTAGAGTTTATGCGTAATATTGGTATGC } \\
\text { ATGGTACTATGTCTATCTCAATCCTTCGAGGAGAACGTTTATGGGGACTTATTGTTTGTCATCATAG } \\
\text { AACACCTTATTATGTCGATTTAGATGGACGTCAAGCTTGTGAATTAGTTGCTCAAGTCTTGGCTTGG } \\
\text { CAAATTGGTGTAATGGAAGAATAATCTAGA }\end{array}$ & This work \\
\hline \multicolumn{3}{|c|}{ 业 } \\
\hline nisR-F & GATGATAAGCTGTCCAAAC & This work \\
\hline nisk-R & TTTAGGATAACTTCTGCCC & This work \\
\hline $682-1 F$ & CTCAGACTTTTCTGGTGTAGTAATCGCAGAGGATAG & This work \\
\hline $682-2 \mathrm{~F}$ & GCATTATCCTGCCAGTGCTGTTCCAGCCCAAGC & This work \\
\hline $682-3 F$ & CCATCTTACGATCTGTTTCACCTTGTCATTTAGAGTTTATGCG & This work \\
\hline $682-1 R$ & CTATCCTCTGCGATTACTACACCAGAAAAGTCTGAG & This work \\
\hline $682-2 R$ & GCTTGGGCTGGAACAGCACTGGCAGGATAATGC & This work \\
\hline $682-3 R$ & CGCATAAACTCTAAATGACAAGGTGAAACAGATCGTAAGATGG & This work \\
\hline
\end{tabular}

\section{Bacterial viability}

The number of colony forming units $(\mathrm{CFU}) / \mathrm{cm}^{2}$ was determined by using the drop-plate method [31]. Long term stationary culture viability was determined by plating tenfold dilutions without antibiotic. To determine $\mathrm{CFU} / \mathrm{cm}^{2}$ in different parts of the intestine the contents of stomach, small intestine, caecum and large intestine were aseptically squeezed out and resuspended in 500 $\mu \mathrm{L}$ PBS, vortexed vigorously and briefly centrifuged (4 s spin). Ten-fold dilutions of the supernatant were plated on chloramphenicol-containing GM-17 plates using the drop-plate method [31]. The CFU/ $\mathrm{cm}^{2}$ was normalized to the weight of the intestinal content.

\section{IRFP cloning}

The IRFP amino acid sequence [8] was back-translated and codon-optimized for L. lactis, yielding irfp 713 gene, which was obtained from Geneart (Table 1). The gene was cloned to pNZ8148, pMSP3545 and pNZRK via $N c o I / X b a I$ sites. pNZRK was prepared by digesting pNZ8148 with SalI, blunting and blunt-end ligation with nisRK PCR amplicon. The latter was obtained by 
using nisR-F/nisK-R primer pair on pMSP3545 template. pNZRK was prepared for the use of PnisA promoter in Lb. plantarum ATCC 8014, because its genome does not contain nisRK genes. pMA-T-IRFP713 was used as a template to introduce mutations E180V, T202A and V254C by using QuikChange II Site-Directed Mutagenesis Kit (Stratagene). Primer pairs 682-1F/682-1R, 682-2F/682$2 \mathrm{R}$ and $682-3 \mathrm{~F} / 682-3 \mathrm{R}$ were used sequentially to obtain irfp682 gene [8]. All plasmids were verified by nucleotide sequencing performed by GATC Biotech (Germany). KOD polymerase was used for PCR amplification. Restriction enzymes were from New England Biolabs and Fermentas. L. lactis and Lb. plantarum were transformed according to Holo [32] and Berthier [33], respectively, with electroporation, using Gene Pulser II apparatus (Biorad). E. coli was transformed with heat-shock.

\section{Expression of IRFP variants}

Overnight cultures of bacteria harboring appropriate plasmids were diluted (1:100) in fresh medium and grown to optical density $\left(\mathrm{OD}_{600}\right) 2.50-3.00$. Required exogenous chromophore biliverdin was provided in bacterial growth medium when culturing bacteria for both in vitro and in vivo experiments. L. lactis cultures were induced with $25 \mathrm{ng} / \mathrm{mL}$ nisin (Fluka) at $\mathrm{OD}_{600}=0.80$ and incubated for a further $3 \mathrm{~h}$; no induction was necessary for Lactobacillus and Escherichia cultures. Bacterial cultures were centrifuged at $5000 \mathrm{~g}$, resuspended in an appropriate volume of $10 \% \mathrm{w} / \mathrm{v}$ sucrose solution and stored at $4{ }^{\circ} \mathrm{C}$ before administration.

\section{Measurement of IRFP fluorescence in bacterial cultures}

Aliquots of cell cultures $(200 \mu \mathrm{l})$ were transferred to black, flat-bottom 96-well plates (Greiner). Fluorescence was measured on an Infinite M1000 microplate reader (Tecan) [27], with excitation/emission at $690 / 713 \mathrm{~nm}$ for IRFP713, or 663/682 nm for IRFP682. Fluorescence intensity was normalized to a cell density $\mathrm{OD}_{600}=1.0$. Excitation and emission spectra were recorded between 600 and $800 \mathrm{~nm}$ at $2 \mathrm{~nm}$ intervals, using the appropriate excitation and emission maxima $(663 / 682 \mathrm{~nm}$ for IRFP682; 690/713 $\mathrm{nm}$ for IRFP713). All the measurements were made in triplicate.

\section{Imaging of IRFP-expressing bacteria in vivo in mice}

Fifty 8 week-old FVB mice were bred in the animal facility at the Jozef Stefan Institute. They were housed in pathogen-free conditions, with food and water ad libitum. Alfalfa-free Teklad global rodent diet 2016 was used to minimize background intestinal fluorescence [34] at least 4 days before the start of experiments. Maximum volumes of $200 \mu \mathrm{L}$ of bacteria were administered by oral gavage. Bacteria were kept at
$4{ }^{\circ} \mathrm{C}$ for 2 days prior to administration to ensure stable fluorescence.

An IVIS Spectrum in vivo imaging system (PerkinElmer) was used for fluorescence imaging of mice. Mice were anesthetized with isoflurane (Forane). Spectral unmixing of IRFP713 and background fluorescence signals was performed by recording sequences of images using the following excitation/emission filter pairs: $675 / 720 \mathrm{~nm}$, $675 / 740 \mathrm{~nm}, 675 / 760 \mathrm{~nm}, 605 / 660 \mathrm{~nm}, 605 / 680 \mathrm{~nm}$, $605 / 700 \mathrm{~nm}, 605 / 720 \mathrm{~nm}, 605 / 740 \mathrm{~nm}$ and $605 / 760 \mathrm{~nm}$. Spectral unmixing of IRFP682, IRFP713 and background fluorescence signals was performed by recording a sequence of images using the following excitation/emission filter pairs: $640 / 680 \mathrm{~nm}, 640 / 700 \mathrm{~nm}, 640 / 720 \mathrm{~nm}$, $640 / 740 \mathrm{~nm}, 640 / 760 \mathrm{~nm}, 640 / 780 \mathrm{~nm}, 675 / 720 \mathrm{~nm}$, $675 / 740 \mathrm{~nm}, 675 / 760 \mathrm{~nm}, 605 / 660 \mathrm{~nm}, 605 / 680 \mathrm{~nm}$, $605 / 700 \mathrm{~nm}, 605 / 720 \mathrm{~nm}, 605 / 740 \mathrm{~nm}$ and $605 / 760 \mathrm{~nm}$. Instrument background fluorescence was removed by using the adaptive fluorescence background subtraction tool. Exposure time was adjusted to obtain count numbers between 600 and 60,000. The region of interest (ROI) was set manually and radiant efficiency (photons s $\mathrm{sm}^{-1}$ steradian $^{-1}$ per $\mu \mathrm{W} \mathrm{cm}^{-2}$ ) was determined when appropriate. Fluorescence tomography (FLIT) was performed by recording a trans-illumination sequence of eight images. Images were analyzed using Living Image, version 4.3.1.

When required, mice were euthanized by cervical dislocation. This was followed by exposure of the abdominal cavity and removal of the intestine from stomach to rectum.

\section{Ethics statement}

All experimental procedures were carried out in accordance with institutional and national guidelines and were approved by the Administration of the Republic of Slovenia for food safety, veterinary sector and plant production (Permit No. U34401-2/2014/6). All the efforts were made to minimize animal suffering.

\section{Additional files}

Additional file 1: Figure $\mathbf{S 1}$. Time-dependent viability (A) and stability of IRFP713 fluorescence (B) of the stationary phase L. lactis culture expressing IRFP713 (red), or empty vehicle control (without irfp713 gene; blue). The bacterial culture was stored at $4^{\circ} \mathrm{C}$ for 56 days.

Additional file 2: Figure S2. Representative example of spectral unmixing of IRFP713 signal from background signal. A: collection of images recorded with different filter pair combinations (see Methods). B: unmixed background (left) and IRFP713 signal (right). Color bar indicates radiant efficiency.

Additional file 3: Figure S3. Representative example of spectral unmixing of IRFP713, IRFP682 and background signal. A: A collection of images recorded with different filter pair combinations (see Methods). B: unmixed background (top), IRFP713 (bottom left) and IRFP682 signal (bottom right). Color bar indicates radiant efficiency. 


\section{Abbreviations}

BV: biliverdin; CFU: colony-forming unit; COMP: composite image; ECO: Escherichia coli; FLIT: fluorescence imaging tomography; GFP: green fluorescent protein; GM17: M17 medium with $0.5 \%$ glucose; IRFP: infrared fluorescent protein; LAB: lactic acid bacteria; LAC: Lactococcus lactis; LB: lysogeny broth; MRS: De Man, Rogosa and Sharpe medium; NIS: nisin; $\mathrm{OD}_{600}$ : optical density at $600 \mathrm{~nm} ;$ PLA: Lactobacillus plantarum.

\section{Authors' contributions}

$A B$ prepared recombinant bacteria, characterized them in vitro and drafted the manuscript. JZ carried out animal experiments and analyzed the data. MB participated in the animal experiments and data analysis. BT and BŠ participated in the design and coordination of the study and helped to draft the manuscript. All authors read and approved the final manuscript.

\section{Author details}

1 Department of Biotechnology, Jožef Stefan Institute, Jamova 39, 1000 Ljubljana, Slovenia. ${ }^{2}$ Department of Biochemistry and Molecular and Structural Biology, Jožef Stefan Institute, Jamova 39, 1000 Ljubljana, Slovenia. ${ }^{3}$ Centre of Excellence for Integrated Approaches in Chemistry and Biology of Proteins, Jamova 39, 1000 Ljubljana, Slovenia. ${ }^{4}$ Faculty of Chemistry and Chemical Technology, University of Ljubljana, 1000 Ljubljana, Slovenia. ${ }^{5}$ Faculty of Pharmacy, University of Ljubljana, Aškerčeva 7, 1000 Ljubljana, Slovenia.

\section{Acknowledgements}

The authors are grateful to Prof. Roger Pain for critical reading of the manuscript. The work was supported by the Slovenian Research Agency grants P1-0140 (B. T.) and J1-5450 (B. Š.).

\section{Competing interests}

The authors declare that they have no competing interests.

Received: 12 June 2015 Accepted: 5 November 2015 Published online: 14 November 2015

\section{References}

1. Doyle TC, Burns SM, Contag CH. In vivo bioluminescence imaging for integrated studies of infection. Cell Microbiol. 2004;6(4):303-17.

2. Calvo-Alvarez E, Stamatakis K, Punzon C, Alvarez-Velilla R, Tejeria A, Escudero-Martinez JM, et al. Infrared fluorescent imaging as a potent tool for in vitro, ex vivo and in vivo models of visceral leishmaniasis. PLoS Negl Trop Dis. 2015;9(3):e0003666.

3. Choy G, O'Connor S, Diehn FE, Costouros N, Alexander HR, Choyke P, et al. Comparison of noninvasive fluorescent and bioluminescent small animal optical imaging. Biotechniques. 2003;35(5):1022-6.

4. Ntziachristos $V$, Bremer C, Weissleder R. Fluorescence imaging with nearinfrared light: new technological advances that enable in vivo molecular imaging. Eur Radiol. 2003;13(1):195-208.

5. Frangioni JV. In vivo near-infrared fluorescence imaging. Curr Opin Chem Biol. 2003;7(5):626-34

6. Umezawa K, Citterio D, Suzuki K. New trends in near-infrared fluorophores for bioimaging. Anal Sci. 2014;30(3):327-49.

7. Shu X, Royant A, Lin MZ, Aguilera TA, Lev-Ram V, Steinbach PA, et al. Mammalian expression of infrared fluorescent proteins engineered from a bacterial phytochrome. Science. 2009;324(5928):804-7.

8. Filonov GS, Piatkevich KD, Ting LM, Zhang J, Kim K, Verkhusha W. Bright and stable near-infrared fluorescent protein for in vivo imaging. Nat Biotechnol. 2011;29(8):757-61.

9. Shcherbakova DM, Verkhusha W. Near-infrared fluorescent proteins for multicolor in vivo imaging. Nat Methods. 2013;10(8):751-4.

10. Aureli P, Capurso L, Castellazzi AM, Clerici M, Giovannini M, Morelli L, et al. Probiotics and health: an evidence-based review. Pharmacol Res. 2011;63(5):366-76.

11. Foligne B, Daniel C, Pot B. Probiotics from research to market: the possibilities, risks and challenges. Curr Opin Microbiol. 2013;16(3):284-92.

12. Wells JM. Immunomodulatory mechanisms of lactobacilli. Microb Cell Fact. 2011;10(Suppl 1):S17.
13. Martin R, Miquel S, Ulmer J, Kechaou N, Langella P, Bermudez-Humaran LG. Role of commensal and probiotic bacteria in human health: a focus on inflammatory bowel disease. Microb Cell Fact. 2013;12:71.

14. Berlec A, Ravnikar M, Strukelj B. Lactic acid bacteria as oral delivery systems for biomolecules. Pharmazie. 2012;67(11):891-8.

15. Daniel C, Roussel Y, Kleerebezem M, Pot B. Recombinant lactic acid bacteria as mucosal biotherapeutic agents. Trends Biotechnol. 2011;29(10):499-508.

16. Steidler L, Hans W, Schotte L, Neirynck S, Obermeier F, Falk W, et al. Treatment of murine colitis by Lactococcus lactis secreting interleukin-10. Science. 2000;289(5483):1352-5.

17. Ravnikar M, Strukelj B, Obermajer N, Lunder M, Berlec A. Engineered lactic acid bacterium Lactococcus lactis capable of binding antibodies and tumor necrosis factor alpha. Appl Environ Microbiol. 2010;76(20):6928-32.

18. Daniel C, Poiret S, Dennin V, Boutillier D, Pot B. Bioluminescence imaging study of spatial and temporal persistence of Lactobacillus plantarum and Lactococcus lactis in living mice. Appl Environ Microbiol. 2013;79(4):1086-94

19. Drouault S, Corthier G, Ehrlich SD, Renault P. Survival, physiology, and lysis of Lactococcus lactis in the digestive tract. Appl Environ Microbiol. 1999;65(11):4881-6.

20. Wang Y, Wang J, Dai W. Use of GFP to trace the colonization of Lactococcus lactis WH-C1 in the gastrointestinal tract of mice. J Microbiol Methods. 2011:86(3):390-2.

21. Geoffroy MC, Guyard C, Quatannens B, Pavan S, Lange M, Mercenier A. Use of green fluorescent protein to tag lactic acid bacterium strains under development as live vaccine vectors. Appl Environ Microbiol. 2000;66(1):383-91.

22. Russo P, Iturria I, Mohedano ML, Caggianiello G, Rainieri S, Fiocco D, et al. Zebrafish gut colonization by mCherry-labelled lactic acid bacteria. Appl Microbiol Biotechnol. 2015;99(8):3479-90.

23. Yu QH, Dong SM, Zhu WY, Yang Q. Use of green fluorescent protein to monitor Lactobacillus in the gastro-intestinal tract of chicken. FEMS Microbiol Lett. 2007;275(2):207-13.

24. Mierau I, Kleerebezem M. 10 years of the nisin-controlled gene expression system (NICE) in Lactococcus lactis. Appl Microbiol Biotechnol. 2005;68(6):705-17.

25. Kleerebezem M, Beerthuyzen MM, Vaughan EE, de Vos WM, Kuipers OP. Controlled gene expression systems for lactic acid bacteria: transferable nisin-inducible expression cassettes for Lactococcus, Leuconostoc, and Lactobacillus spp. Appl Environ Microbiol. 1997;63(11):4581-4.

26. van der Meer JR, Polman J, Beerthuyzen MM, Siezen RJ, Kuipers OP, De Vos WM. Characterization of the Lactococcus lactis nisin A operon genes nisP, encoding a subtilisin-like serine protease involved in precursor processing, and nisR, encoding a regulatory protein involved in nisin biosynthesis. J Bacteriol. 1993;175(9):2578-88.

27. Berlec A, Strukelj B. A high-throughput biliverdin assay using infrared fluorescence. J Vet Diagn Invest. 2014;26(4):521-6.

28. Hock AK, Lee P, Maddocks OD, Mason SM, Blyth K, Vousden KH. iRFP is a sensitive marker for cell number and tumor growth in high-throughput systems. Cell Cycle. 2014;13(2):220-6.

29. Padmanabhan P, Grosse J, Asad AB, Radda GK, Golay X. Gastrointestinal transit measurements in mice with 99mTc-DTPA-labeled activated charcoal using NanoSPECT-CT. EJNMMI Res. 2013;3(1):60.

30. Krumholz A, Shcherbakova DM, Xia J, Wang LV, Verkhusha W. Multicontrast photoacoustic in vivo imaging using near-infrared fluorescent proteins. Sci Rep. 2014:4:3939.

31. Herigstad B, Hamilton M, Heersink J. How to optimize the drop plate method for enumerating bacteria. J Microbiol Methods. 2001;44(2):121-9.

32. Holo H, Nes IF. High-frequency transformation, by electroporation, of Lactococcus lactis subsp. cremoris grown with glycine in osmotically stabilized media. Appl Environ Microbiol. 1989;55(12):3119-23.

33. Berthier F, Zagorec M, Champomier-Verges M, Ehrlich SD, Morel-Deville F. Efficient transformation of Lactobacillus sake by electroporation. Microbiology. 1996;142(5):1273-9.

34. Troy T, Jekic-McMullen D, Sambucetti L, Rice B. Quantitative comparison of the sensitivity of detection of fluorescent and bioluminescent reporters in animal models. Mol Imaging. 2004;3(1):9-23. 
35. de Ruyter PG, Kuipers OP, de Vos WM. Controlled gene expression systems for Lactococcus lactis with the food-grade inducer nisin. Appl Environ Microbiol. 1996;62(10):3662-7.

36. Kuipers OP, de Ruyter PGGA, Kleerebezem M, de Vos WM. Quorum sensing-controlled gene expression in lactic acid bacteria. J Biotechnol. 1998;64(1):15-21.
37. Bryan EM, Bae T, Kleerebezem M, Dunny GM. Improved vectors for nisin-controlled expression in gram-positive bacteria. Plasmid. 2000;44(2):183-90.

Submit your next manuscript to BioMed Central and take full advantage of:

- Convenient online submission

- Thorough peer review

- No space constraints or color figure charges

- Immediate publication on acceptance

- Inclusion in PubMed, CAS, Scopus and Google Scholar

- Research which is freely available for redistribution

Submit your manuscript at

www.biomedcentral.com/submit

() BioMed Central 